\title{
Large-Scale Metal AM for Stamping Dies
}
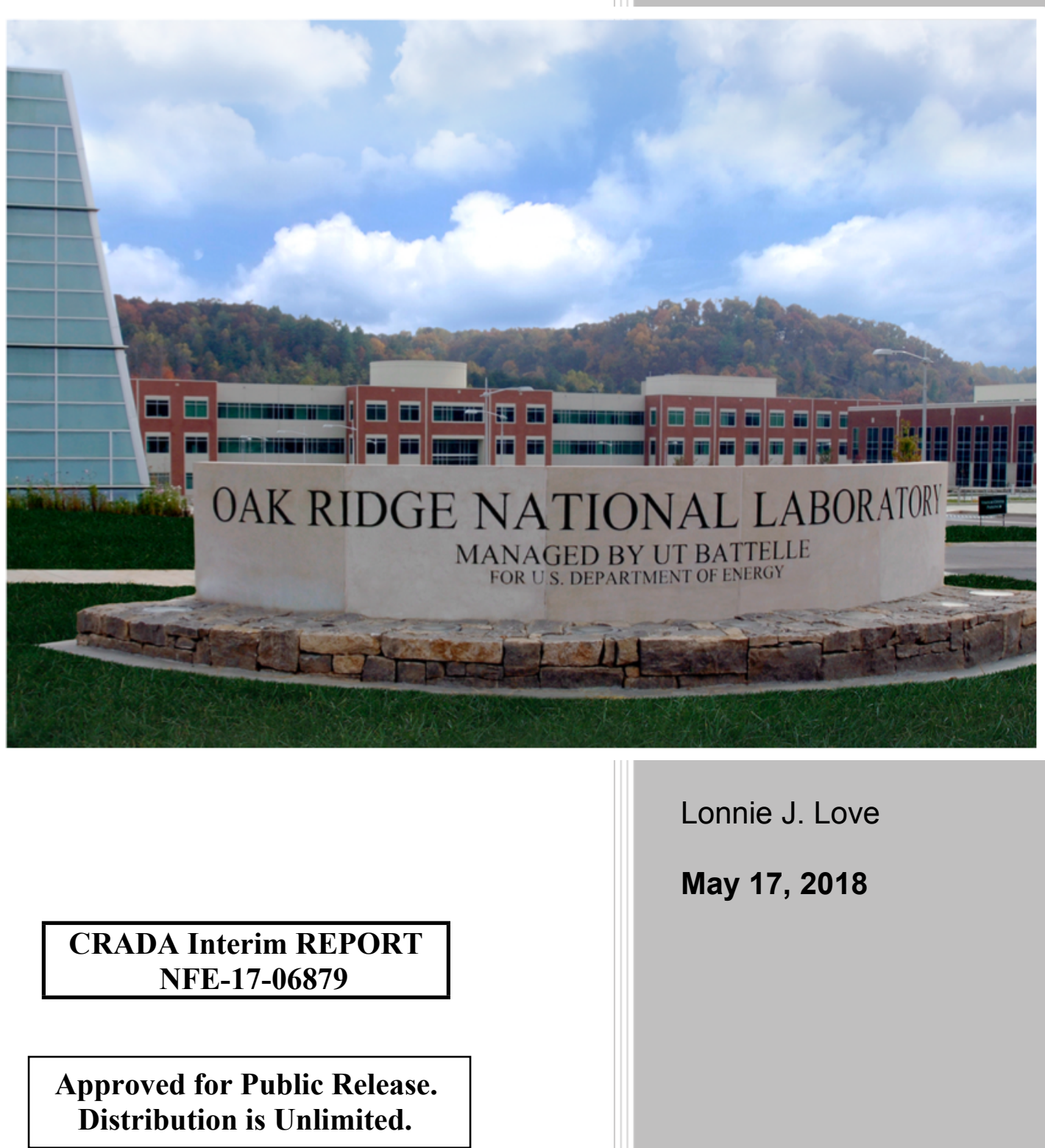

Lonnie J. Love

May 17, 2018 


\section{DOCUMENT AVAILABILITY}

Reports produced after January 1, 1996, are generally available free via US Department of Energy (DOE) SciTech Connect.

Website http://www.osti.gov/scitech/

Reports produced before January 1, 1996, may be purchased by members of the public from the following source:

National Technical Information Service
5285 Port Royal Road
Springfield, VA 22161
Telephone 703-605-6000 (1-800-553-6847)
TDD 703-487-4639
Fax 703-605-6900
E-mail info@ntis.gov
Website http://www.ntis.gov/help/ordermethods.aspx

Reports are available to DOE employees, DOE contractors, Energy Technology Data Exchange representatives, and International Nuclear Information System representatives from the following source:

Office of Scientific and Technical Information

PO Box 62

Oak Ridge, TN 37831

Telephone 865-576-8401

Fax 865-576-5728

E-mail reports@osti.gov

Website http://www.osti.gov/contact.html

This report was prepared as an account of work sponsored by an agency of the United States Government. Neither the United States Government nor any agency thereof, nor any of their employees, makes any warranty, express or implied, or assumes any legal liability or responsibility for the accuracy, completeness, or usefulness of any information, apparatus, product, or process disclosed, or represents that its use would not infringe privately owned rights. Reference herein to any specific commercial product, process, or service by trade name, trademark, manufacturer, or otherwise, does not necessarily constitute or imply its endorsement, recommendation, or favoring by the United States Government or any agency thereof. The views and opinions of authors expressed herein do not necessarily state or reflect those of the United States Government or any agency thereof. 
ORNL/TM-2018/865

CRADA/NFE-17-06879

Energy and Transportation Sciences Division

Advanced Manufacturing Office

\title{
Large-Scale Metal AM for Stamping Dies
}

\author{
Authors \\ Lonnie J. Love \\ Mark W. Noakes \\ Andrzej Nycz \\ Christopher J. Masuo \\ Katherine T. Gaul
}

Date Published:

May 17, 2018

\footnotetext{
Prepared by

OAK RIDGE NATIONAL LABORATORY

Oak Ridge, Tennessee 37831-6283

managed by

UT-BATTELLE, LLC

for the

US DEPARTMENT OF ENERGY

under contract DE-AC05-00OR22725
}

Approved For Public Release 


\section{CONTENTS}

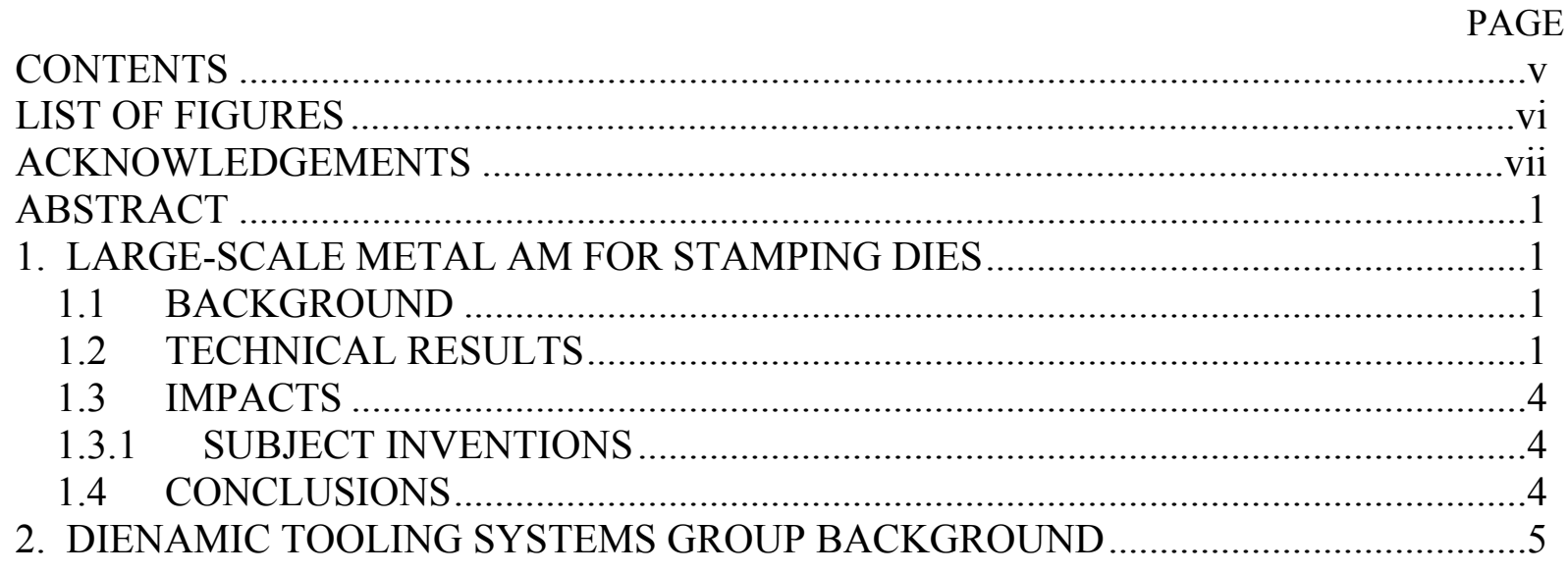




\section{LIST OF FIGURES}

Fig. 1. DTS tool after machining (right) with stamped parts that were manufactured using the

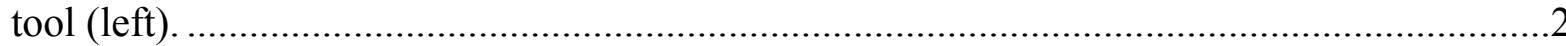

Fig. 2. DTS tool with stamped part attached to illustrate accurate fit. .................................

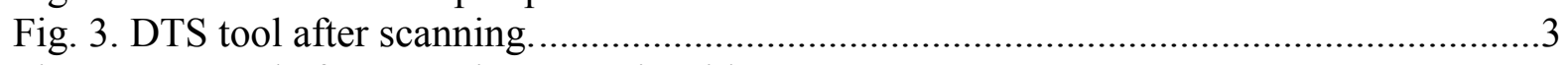

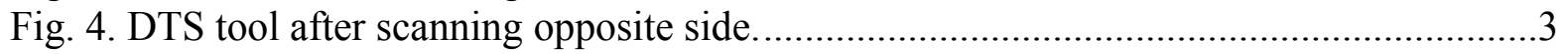




\section{ACKNOWLEDGEMENTS}

This CRADA NFE-17-06879 is conducted as a Technical Collaboration project within the Oak Ridge National Laboratory (ORNL) Manufacturing Demonstration Facility (MDF) sponsored by the US Department of Energy Advanced Manufacturing Office (CPS Agreement Number 24761).

Opportunities for MDF technical collaborations are listed in the announcement "Manufacturing Demonstration Facility Technology Collaborations for US Manufacturers in Advanced

Manufacturing and Materials Technologies" posted at http:/web.ornl.gov/sci/manufacturing/docs/FBO-ORNL-MDF-2013-2.pdf. The goal of technical collaborations is to engage industry partners to participate in short-term, collaborative projects within the Manufacturing Demonstration Facility (MDF) to assess applicability and of new energy efficient manufacturing technologies. Research sponsored by the U.S. Department of Energy, Office of Energy Efficiency and Renewable Energy, Advanced Manufacturing Office, under contract DE-AC0500OR22725 with UT-Battelle, LLC. 


\begin{abstract}
Oak Ridge National Laboratory (ORNL) worked with Dienamic Tooling Systems Group to demonstrate metal additively manufacturing stamping dies and individual details for prototype tooling. This project was completed using the Wolf Robotics metal additive manufacturing system at ORNL's Manufacturing Demonstration Facility. A small stamping die was printed, machined, and tested; the parts formed using that die passed a quality check and were found to be in tolerance.
\end{abstract}

\title{
1. LARGE-SCALE METAL AM FOR STAMPING DIES
}

This phase one technical collaboration project (MDF-TC-2017-118 began on August 1, 2017 and completed on May 17, 2018. The collaboration partner, Dienamic Tooling Systems Group (DTS), is a small business located in Lenoir City, Tennessee. This project aimed to reduce the cost and time consumed to manufacture metal stamping die tools by using metal additive manufacturing. During phase one, a tool was successfully manufactured, machined, and tested at the Manufacturing Demonstration Facility (MDF).

\subsection{BACKGROUND}

DTS designs and builds metal stamping dies for all original equipment manufacturing companies. The MDF helped develop the additive manufacturing process that reduces cost and timing of metal stamping dies, which enables the U.S. tooling and die industry to become more competitive against foreign competition.

DTS is a small-medium enterprise (SME), and this project will develop and refine new metal additive manufacturing technology while increasing an SME's competitiveness. The primary outcome of this phase one project was to validate the feasibility of producing a stamping die tooling using metal additive manufacturing.

\subsection{TECHNICAL RESULTS}

The DTS tool (Fig. 1 and Fig. 2) was printed using ER70S-6 mild steel wire on the Wolf Robotics wire-arc additive manufacturing system. It took approximately 11 hours to fabricate the tool. The part dimensions were 11 1/4" X 5 5/8" X 3 1/2". The as printed weight of the part was 34.5 pounds, and the as machined weight was 28.6 pounds. Additionally, it took approximately one hour to machine to the tool to its final accurate geometry.

After the tool was printed, it was sent to DTS for machining, analysis, and testing. The part was scanned as shown in Figures 3 and 4. No important surfaces were out of geometric specifications. Formed parts were produced and checked for accuracy. All stamped parts passed quality inspection without issues. No data was collected on tool wear as the material used was mild steel and not expected to last in a production environment. 


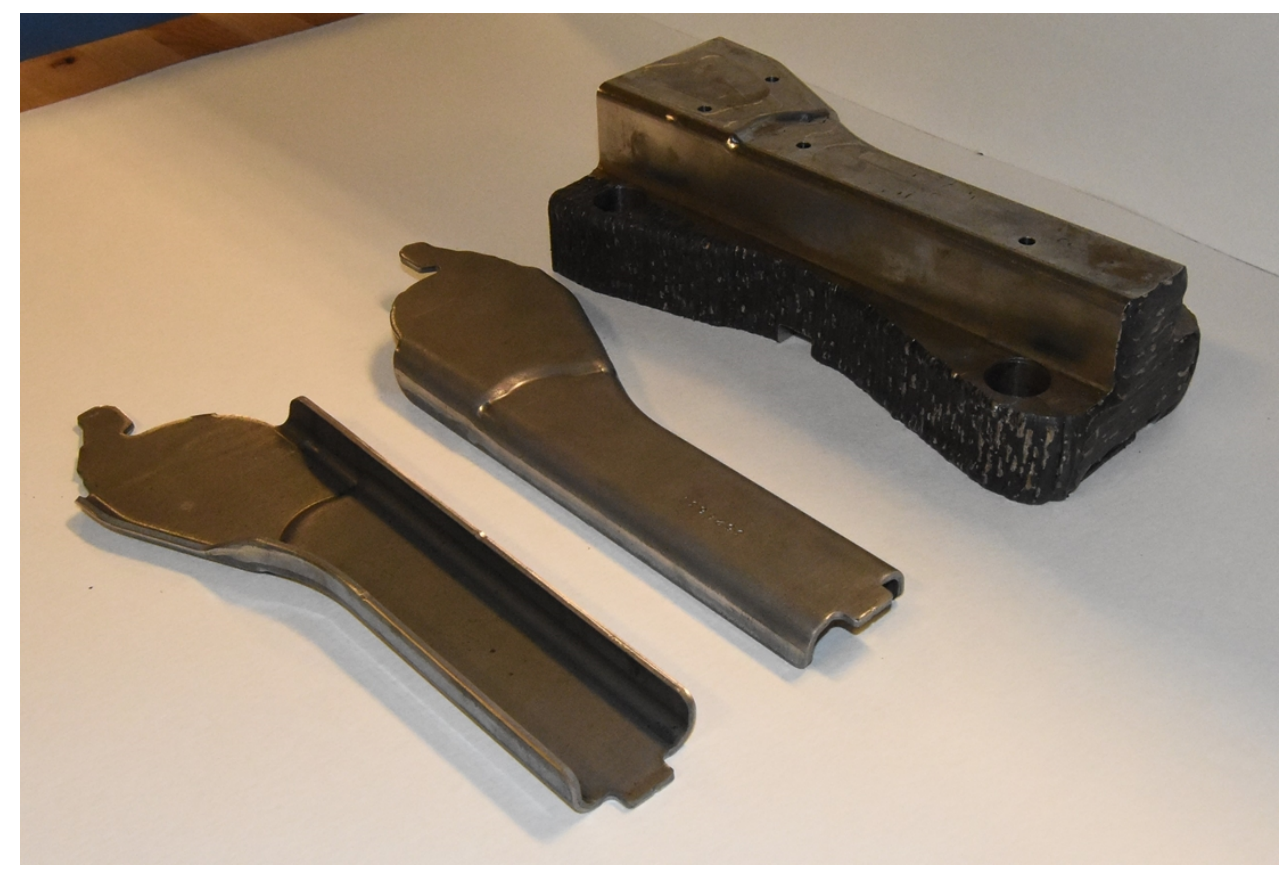

Fig. 1. DTS tool after machining (right) with stamped parts that were manufactured using the tool (left).

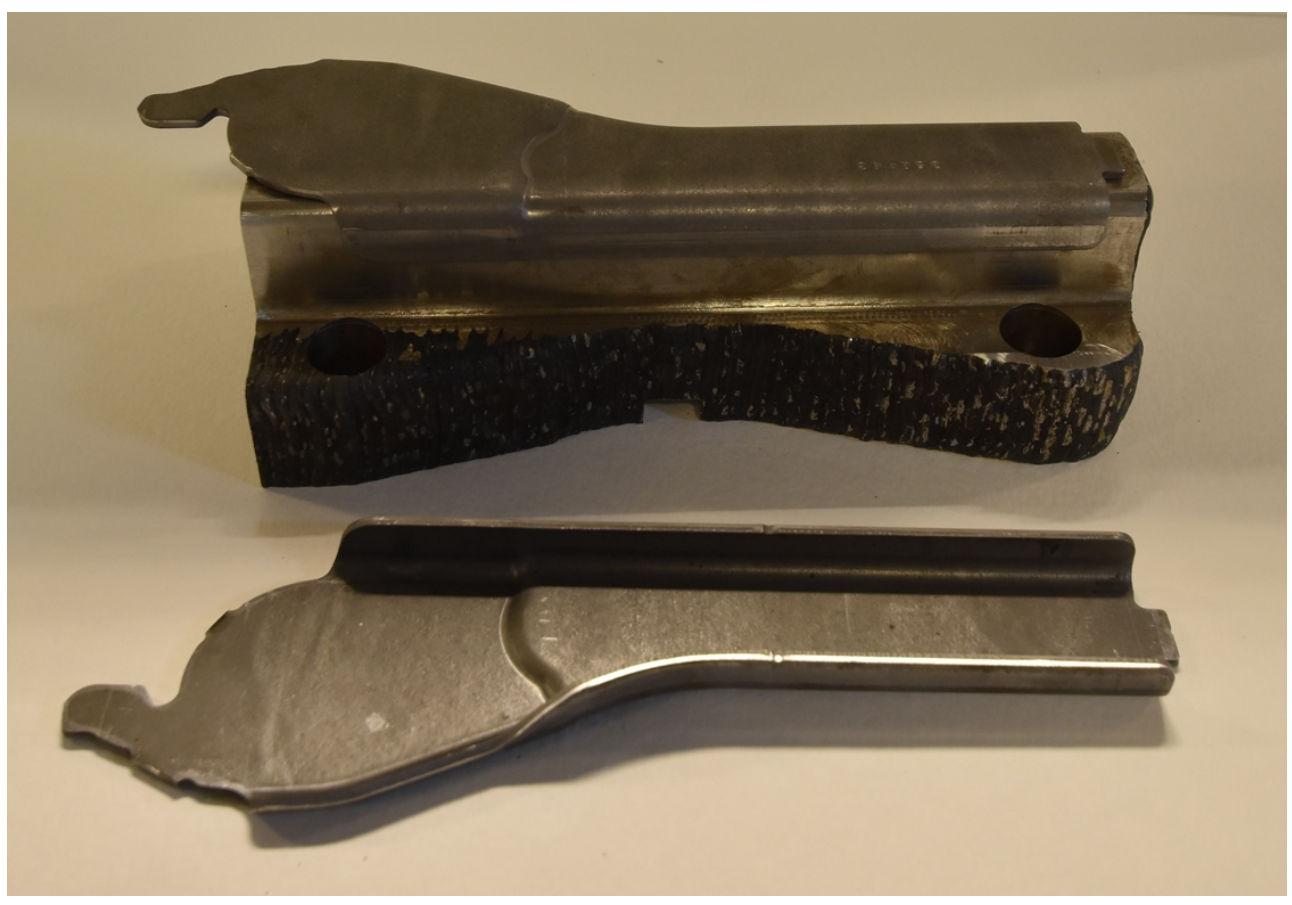

Fig. 2. DTS tool with stamped part attached to illustrate accurate fit. 
DETAIL SEEMS TO HAVE PRINTED CLOSE TO

NOMINAL.

GREEN AREAS ARE WITHIN +/- 1/16".

MAX CRITICAL (+/-1/4") ARE SHOWN IN RED/BLUE.

NO AREAS WERE SIGNIFIGANTLY UNDER NOMINAL.

YOU CAN SEE THE COMPRESED (SHORT) AREA IN GREY. PRINTED DETAIL IS ONLY THE COLORED AREA.

MODEL WAS ALIGNED TO THE SCAN OF THE DETAIL MANUALLY TO GIVE THE BEST OVERALL ALIGNMENT.

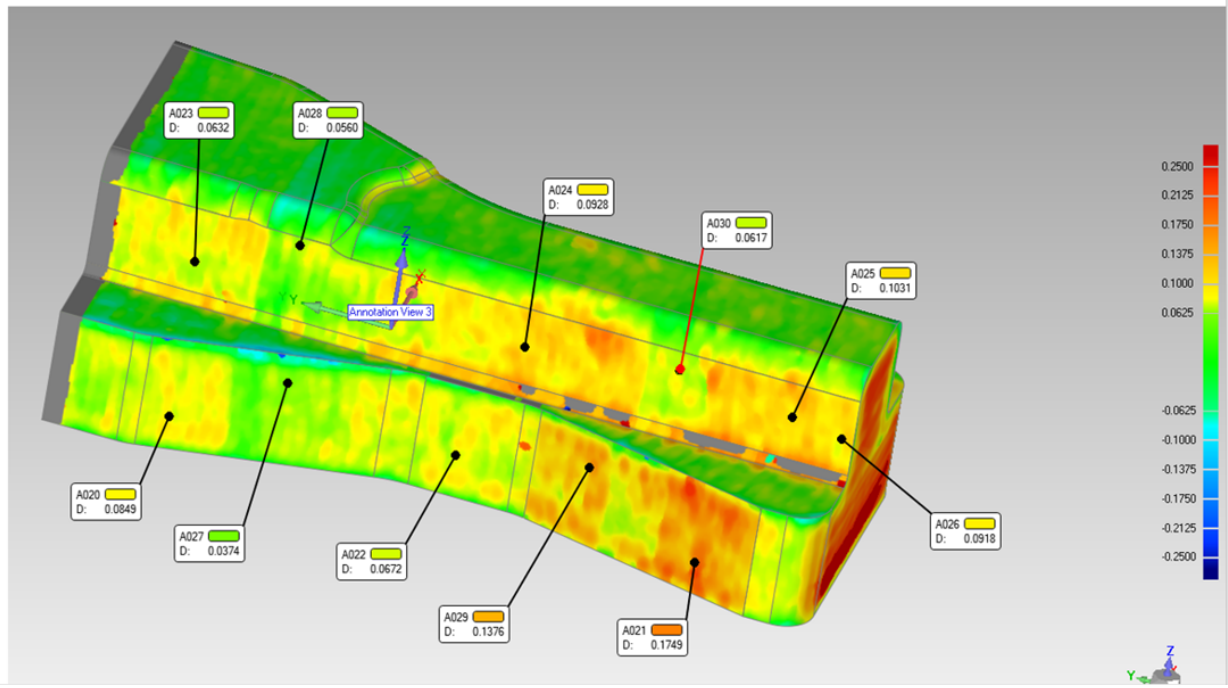

Fig. 3. DTS tool after scanning.

SOLID DETAIL

DETAIL SEEMS TO HAVE PRINTED CLOSE TO

NOMINAL.

GREEN AREAS ARE WITHIN +/- 1/16".

MAX CRITICAL (+/-1/4") ARE SHOWN IN RED/BLUE.

NO AREAS WERE SIGNIFIGANTLY UNDER NOMINAL.

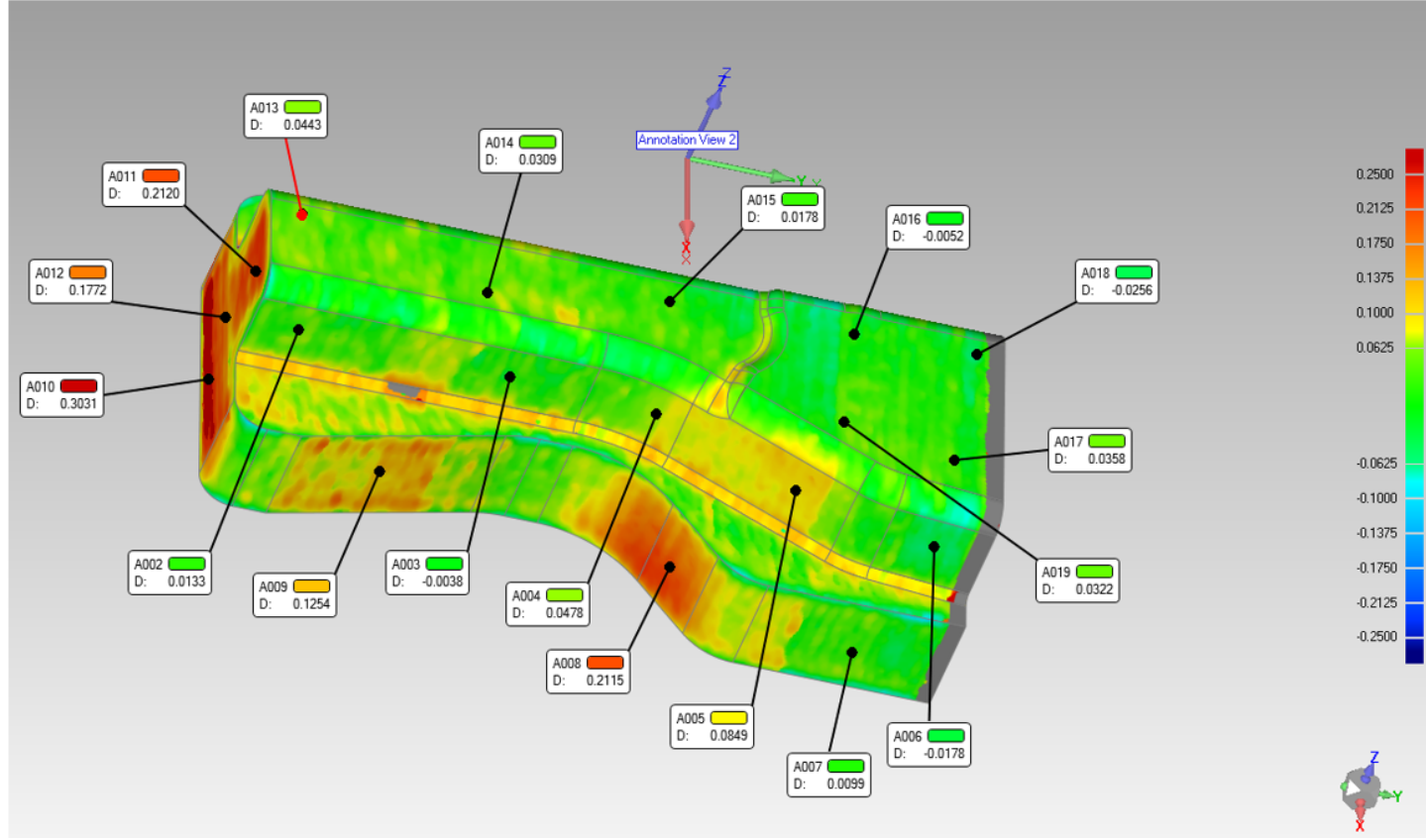

Fig. 4. DTS tool after scanning opposite side. 


\subsection{IMPACTS}

Producing metal stamping dies using additive processes reduces the lead times of tool manufacturing. It also makes North American tool and die makers more competitive in the global market. Reducing raw material needed to produce a stamping die by adding metal to near net shape rather than removing material to net shape offers advantages in material and cost savings as well. Using additive manufacturing reduces required machining process by up to $50 \%$. The additive

process is also extremely useful for prototyping and fabricating quick run parts that automakers need during vehicle development, which allows for shorter lead times and faster reaction time to changes.

\subsubsection{SUBJECT INVENTIONS}

There are no subject inventions associated with this project at this time.

\subsection{CONCLUSIONS}

Overall, this phase one work was considered a complete success. A stamping die tool was designed through a collaborative effort between DTS and ORNL. ORNL additively manufactured the tool. DTS ensured that any necessary finishing work was completed, tested the tool, and determined that the tool was within specifications. The parts made using the tool were inspected for quality and found to be within tolerances.

The initial phase was used to realize the abilities and limitations of the additive process. Follow on work will explore higher strength and harder materials for the production of a more complex tool. Phase two is desired to prove that an additively manufactured part can be used in the same environment as a traditionally manufactured part. 


\section{DIENAMIC TOOLING SYSTEMS GROUP BACKGROUND}

DTS is a Tooling Systems Group company. The Tooling Systems Group (TSG) is a collaboration of independently owned and operated companies that specialize in tooling, equipment, and service for manufacturers around the world. DTS designs, builds, re-engineers, and services

medium to large sized sheet metal stamping dies and tooling. With several hundred dies under its belt, DTS has experience with:

- $\quad$ progressive, transfer and line dies

- deep draws, complex extrusions, and over bends

- standard, sound deadening, heat shield, and heavy thickness materials

- integration into automated assembly lines

DTS has essential equipment, processes, and staff on-site at its 50,000 sq. ft. facility to manufacture many die and tools efficiently. DTS has the following equipment: (4) Tryout presses that range in size up to 2,500-tons (108" x 200" bed capable of running 108" x 220" dies), (7) Overhead cranes that are capable of lifting up to 40-tons, (4) High-speed CNC mills with work areas up to X168" x Y72" x Z72", and 70 employees which include: project managers, estimators, designers, die builders, machinist, and administrators. 